The Lure of the Image 



\section{The Lure of the Image}

Epistemic Fantasies of the Moving Camera

\section{Daniel Morgan}

무 
University of California Press

Oakland, California

(C) 202 I by Daniel Morgan

Library of Congress Cataloging-in-Publication Data

Names: Morgan, Daniel, I977- author.

Title: The lure of the image : epistemic fantasies of the moving camera / Daniel Morgan.

Description: Oakland, California : University of California Press, [202I] I Includes bibliographical references and index.

Identifiers: LCCN 2021005040 (print) I LCCN 202 I00504 I (ebook) | ISBN 9780520344259 (cloth) | ISBN 9780520344273 (paperback) | ISBN 9780520975446 (epub)

Subjects: LCSH: Motion pictures-Production and direction. I Motion pictures-Aesthetics. I Cinematography.

Classification: LCC PNI995.9.P7 M57 202I (print) |

LCC PNI995.9.P7 (ebook) I DDC 79I.430I-dc23

LC record available at https://lccn.loc.gov/202 I005040

LC ebook record available at https://lccn.loc.gov/202 I00504 I

Manufactured in the United States of America

$\begin{array}{llllllllll}30 & 29 & 28 & 27 & 26 & 25 & 24 & 23 & 22 & 21\end{array}$

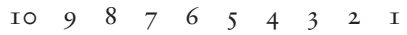


The film image ... is what? A lure.

-Roland Barthes 
